\title{
Cystatin C as a Predictor of In-Hospital Mortality After Exacerbation of COPD
}

\author{
Guoping $\mathrm{Hu} \mathrm{PhD}$, Yankui Wu MB, Yumin Zhou PhD, Yan Yu MB, Weiqiang Liang MB, and \\ Pixin Ran $\mathrm{PhD}$
}

\begin{abstract}
BACKGROUND: COPD is associated with cardiovascular and renal dysfunction. Cystatin C (CysC) is a biomarker of renal function and an independent risk factor for all-cause and cardiovascular mortality among elderly persons. The aim of the study was to examine the prognostic role of CysC for in-hospital mortality in subjects with a COPD exacerbation. METHODS: Upon admission, serum CysC levels and arterial blood gas analysis from 477 subjects with a COPD exacerbation were measured. Clinical characteristics were also recorded. A receiver operating characteristic curve analysis was used to determine the level of $\mathrm{CysC}$ that discriminated survivors from nonsurvivors. Univariate and multiple logistic regression analyses were used to identify the risk factors for in-hospital mortality. To reduce the influence of confounders, subgroup analyses were performed according to the comorbidities, including states of heart failure, renal dysfunction, and $\mathrm{pH}$, $P_{\mathrm{aCO}}$, and $\mathrm{P}_{\mathrm{aO}_{2}}$ levels. RESULTS: During the in-hospital period, 59 subjects died, and 418 subjects recovered. The decedent group showed lower $\mathrm{pH}(7.27 \pm 0.17$ vs $7.38 \pm 0.06, P<.001)$, higher CysC $(2.21 \pm 1.05 \mathrm{mg} / \mathrm{L}$ vs $1.39 \pm 0.54 \mathrm{mg} / \mathrm{L}, P<.001)$, higher $P_{\mathrm{aCO}_{2}}(77 \pm 39 \mathrm{~mm} \mathrm{Hg}$ vs $48 \pm 14 \mathrm{~mm} \mathrm{Hg}, P<.001)$, and lower $P_{\mathrm{aO}_{2}}(74 \pm 32 \mathrm{~mm} \mathrm{Hg}$ vs $84 \pm 26 \mathrm{~mm} \mathrm{Hg}, P<.001)$ levels. The area under the receiver operating characteristic curve for the $\mathrm{CysC}$ prediction of death was 0.77 (95\% CI $0.70-0.84)$. CysC values $\geq 1.59 \mathrm{mg} / \mathrm{L}$ were associated with significantly higher inhospital mortality (relative risk $=5.49,95 \%$ CI 3.24-9.32, $P<.001$ ). Multiple logistic regression analysis showed that $\mathrm{pH}<7.20, \mathrm{CysC} \geq 1.59 \mathrm{mg} / \mathrm{L}$, and heart failure were independent predictors of in-hospital mortality. The subgroup analysis showed that the comorbid states of renal dysfunction, congestive heart failure, and the levels of $\mathrm{pH}, \mathrm{P}_{\mathrm{aCO}}$, and $\mathrm{P}_{\mathrm{aO}_{2}}$ did not alter the conclusion that CysC was a mortality risk factor for subjects with a COPD exacerbation. CONCLUSION: CysC was a strong and independent risk factor for hospital mortality secondary to COPD exacerbation. Key words: COPD exacerbation; cystatin C; mortality; prognosis. [Respir Care 2016;61(7):950-957. (c) 2016 Daedalus Enterprises]
\end{abstract}

\section{Introduction}

COPD is one of the leading causes of morbidity and mortality worldwide. ${ }^{1}$ Because COPD is considered to be

Drs $\mathrm{Hu}, \mathrm{Yu}$, and Liang are affiliated with the Department of Respiratory Medicine, Third Affiliated Hospital of Guangzhou Medical University, Guangzhou, Guangdong, China. Dr Wu is affiliated with the Department of Respiratory Disease, People's Hospital of Guangxi Zhuang Autonomous Region, Guangxi Zhuang Autonomous Region, China. Dr Zhou and Professor Ran are affiliated with the Guangzhou Institute of Respiratory Disease, State Key Laboratory of Respiratory Disease, First Affiliated Hospital of Guangzhou Medical University, Guangzhou, Guangdong, China.

Drs $\mathrm{Hu}$ and $\mathrm{Wu}$ are co-first authors. a systemic disorder, one of its multiple co-morbidities is cardiovascular dysfunction. Epidemiological evidence suggests that impaired lung function is strongly correlated

\footnotetext{
This study was supported by the National Key Technology R\&D Program of the 12th National Five-Year Development Plan 2012BAI05B01 (to Dr Ran) and by the Guangzhou municipal health bureau scientific research fund (201102A213176). The authors have disclosed no conflicts of interest.

Correspondence: Pixin Ran PhD, Guangzhou Institute of Respiratory Disease, First Affiliated Hospital, Guangzhou Medical University, 151 Yanjiang Road, Guangzhou, Guangdong 510120, China. E-mail: pxran@vip.163.com.
}

DOI: $10.4187 /$ respcare.04034 
with increased cardiovascular-related deaths. ${ }^{2,3}$ Cardiac dysfunction may trigger exacerbation in up to $25 \%$ of COPD patients, and acute myocardial infarction and chronic heart failure may be associated with COPD exacerbation, whereas acute respiratory failure itself may lead to right and/or left ventricular failure. ${ }^{4,5}$

Another co-morbidity associated with COPD is renal dysfunction. Gjerde et $\mathrm{al}^{6}$ reported that the prevalence of a glomerular filtration rate of $<60 \mathrm{~mL} / \mathrm{min}$ was $9.6 \%$ in female COPD subjects and $5.1 \%$ in male subjects. Undiagnosed renal failure is a concern, particularly in elderly COPD patients and in COPD patients with cachexia.

Cystatin $\mathrm{C}(\mathrm{Cys} C)$ is a low-molecular weight protein found in the plasma, which is freely filtered by the renal glomerulus and reabsorbed in the tubules, where it is metabolized almost completely. ${ }^{7}$ A serum CysC-based equation has even been proposed to estimate the glomerular filtration rate in patients with chronic kidney disease. ${ }^{8} \mathrm{Re}-$ cent studies have revealed that $\mathrm{Cys} C$ has a predictive and prognostic value in cardiovascular disease, especially coronary artery disease and heart failure. ${ }^{9-13}$ However, the literature on the role of CysC in subjects with COPD exacerbation is sparse. One study that examined the level of CysC in COPD subjects showed that a high CysC concentration may be a potential indicator of impaired lung function and that routinely measuring $\mathrm{CysC}$ may improve the diagnosis and assessment of COPD severity in elderly male subjects. ${ }^{14}$ Another study examined the 1 -y prognostic value of elevated CysC among subjects with exacerbation of chronic lung disease who were hospitalized and showed that $\mathrm{Cys} C$ has no predictive value for mortality in subjects with chronic respiratory disease. ${ }^{15}$ However, no articles have presented an evaluation of the prognostic value of CysC in subjects with COPD exacerbation. It is possible that $\mathrm{CysC}$ measurements can contribute to the early identification of patients at risk for the development of clinically important ventricular dysfunction. We hypothesized that $\mathrm{Cys} C$ exhibits an inverse relationship with the prognosis of COPD exacerbation. Accordingly, the objective of the current study was to explore the in-hospital prognostic value of elevated CysC during COPD exacerbation.

\section{Methods}

\section{Study Design}

This was a prospective study conducted in the Third Affiliated Hospital of Guangzhou Medical University, Guangzhou, Guangdong, China, between July 2010 and July 2013 in subjects hospitalized with a diagnosis of COPD exacerbation. Subjects were included if the following criterion was met: a diagnosis of COPD according to the criteria set by the Global Initiative for Chronic Obstructive Lung Disease (ie, a post-bronchodilator $\mathrm{FEV}_{1} / \mathrm{FVC}$ of $<0.7$

\section{QUICK LOOK}

\section{Current knowledge}

COPD is considered to be a systemic disorder, and cardiovascular and renal dysfunction are 2 of its multiple co-morbidities. Cystatin C (CysC) has a predictive and prognostic value in cardiovascular disease, especially coronary artery disease and heart failure. Understanding the prognostic value of $\mathrm{Cys} C$ in patients with COPD exacerbation could contribute to the early identification of patients at risk for death.

\section{What this paper contributes to our knowledge}

In this cohort study, univariate and multiple logistic regression analysis showed that $\mathrm{pH}, \mathrm{Cys} C$, and heart failure were independent predictors of in-hospital mortality; the comorbid states of renal dysfunction, congestive heart failure, and levels of $\mathrm{pH}, \mathrm{P}_{\mathrm{aCO}}$, and $\mathrm{P}_{\mathrm{aO}_{2}}$ did not alter the conclusion that $\mathrm{CysC}$ was a mortality risk factor for subjects with COPD exacerbation. CysC may be used to evaluate the in-hospital mortality for patients with COPD exacerbation.

according to the records of lung function testing at our hospital). COPD exacerbation was defined by the presence of an increase in at least 2 of 3 symptoms: dyspnea, cough, and sputum purulence. Patients were excluded if the primary reason for their hospitalization was not an exacerbation of COPD according to their medical history (information from interview and clinical records provided by the patients). Patients diagnosed with coronary ischemia were also excluded along with those diagnosed with chronic renal insufficiency, renal failure, or nephritis before the COPD exacerbation. However, we did not exclude subjects who had been diagnosed with heart failure. Subjects' treatment was not influenced by participation in the study. The study was carried out according to the principles of the Declaration of Helsinki and was approved by the ethics committee of the Third Affiliated Hospital of Guangzhou Medical University.

\section{Biochemical Measurements}

The age, sex, and smoking status of subjects were recorded at the time of admission. CysC levels were measured within $24 \mathrm{~h}$ of admission. Scattering immunoturbidimetry was used to measure the serum CysC concentration. Serum creatinine levels were assayed using the Jaffe method on a Hitachi Modular Pre-Analytics Plus system (Roche Diagnostics, Basel, Switzerland). The glomerular filtration rate was estimated within $24 \mathrm{~h}$ of admission by the sim- 


\section{CysC Predicts Mortality in COPD Exacerbation}

plified Modification of Diet in Renal Disease equation. ${ }^{16}$ Renal dysfunction was defined as a glomerular filtration rate of $<90 \mathrm{~mL} / \mathrm{min}$. An arterial blood gas analysis $\left(\mathrm{P}_{\mathrm{aO}}\right.$, $\mathrm{P}_{\mathrm{aCO}_{2}}$, and $\mathrm{pH}$ ) was performed upon admission. Congestive heart failure was diagnosed according to the Chinese guidelines published in 2007 for the diagnosis and management of chronic heart failure, ${ }^{17}$ which included typical symptoms of heart failure (breathlessness, orthopnea, paroxysmal nocturnal dyspnea, reduced exercise tolerance, fatigue, tiredness, increased time to recover after exercise, and ankle swelling); typical signs of heart failure (elevated jugular venous pressure, hepatojugular reflux, a third heart sound, a laterally displaced apical impulse, and a cardiac murmur); and a reduced left ventricular ejection fraction.

\section{Statistical Analyses}

The primary outcomes of interest were in-hospital mortality and factors associated with in-hospital mortality. Continuous variables are presented as the means $\pm \mathrm{SD}$. Categorical variables are presented as $n(\%)$. Comparisons between groups were made using analysis of variance (for continuous variables) or a chi-square test (for categorical variables). Logistic regression analysis was used to identify independent variables associated with death. To limit the number of events per variable, only variables yielding univariate associations with $P \leq .05$ were included in the logistic regression model. Receiver operating characteristic curve analysis was used to optimize the minimal level of $\mathrm{CysC}$ that predicted mortality. Subgroup analyses were performed according to the comorbidities, including states of heart failure, renal dysfunction, and the levels of $\mathrm{pH}$, $\mathrm{P}_{\mathrm{aO}}$, and $\mathrm{P}_{\mathrm{aCO}_{2}}$. Nonparametric data are reported as the mean $\pm \mathrm{SD}$. Across-groups comparison of 3 groups was performed using the non-parametric Kruskal-Wallis test followed by the Dunn post hoc test. Direct comparisons between 2 groups were performed with the nonparametric Mann-Whitney test. Stata 7.0 (Stata, College Station, Texas) and GraphPad Prism 5.0 (GraphPad Software, La Jolla, California) were used for all calculations. A 2 -sided $P$ value of $<.05$ was considered to be statistically significant.

\section{Results}

A total of 477 subjects with COPD exacerbation were included in our cohort study. The differences between survivors and non-survivors among the hospitalized subjects are listed in Table 1. The subjects who died were more likely to have renal dysfunction. In addition, the subjects who died were significantly more hypercapnic $\left(\mathrm{P}_{\mathrm{aCO}_{2}}=\right.$ $77 \pm 39 \mathrm{~mm} \mathrm{Hg})$ and older $(79.9 \pm 9.7 \mathrm{y})$ than the survivors $\left(\mathrm{P}_{\mathrm{aCO}_{2}}=48 \pm 14 \mathrm{~mm} \mathrm{Hg}\right.$ and age $76.9 \pm 9.3 \mathrm{y}$, respectively). There was no difference in lung function between survivors and those who died. The $\mathrm{pH}$ and $\mathrm{P}_{\mathrm{aO}_{2}}$
Table 1. Baseline Characteristics and Survival of Subjects Hospitalized With COPD Exacerbation

\begin{tabular}{|c|c|c|c|}
\hline Subject Characteristics & $\begin{array}{l}\text { Survivors } \\
(n=418)\end{array}$ & $\begin{array}{l}\text { Non-Survivors } \\
\quad(n=59)\end{array}$ & $P$ \\
\hline Age, mean \pm SD y & $76.9 \pm 9.3$ & $79.9 \pm 9.7$ & .02 \\
\hline Male/female sex, $n$ & $312 / 106$ & $45 / 14$ & .46 \\
\hline Nonsmokers/smokers, $n$ & $80 / 338$ & $8 / 51$ & .30 \\
\hline $\mathrm{FEV}_{1} / \mathrm{FVC}$, mean $\pm \mathrm{SD}$ & $55.0 \pm 9.2$ & $53.6 \pm 10.8$ & .28 \\
\hline $\mathrm{FEV}_{1}$, mean $\pm \mathrm{SD} \%$ predicted & $62.1 \pm 21.0$ & $59.9 \pm 21.2$ & .45 \\
\hline CHF (no/yes), $n$ & $348 / 70$ & $29 / 30$ & $<.001$ \\
\hline $\mathrm{RD}$ (no/yes), $n$ & $353 / 65$ & $31 / 28$ & $<.001$ \\
\hline $\mathrm{P}_{\mathrm{aCO}_{2}}$, mean $\pm \mathrm{SD} \mathrm{mm} \mathrm{Hg}$ & $48 \pm 14$ & $77 \pm 39$ & $<.001$ \\
\hline $\mathrm{P}_{\mathrm{aO}_{2}}$, mean $\pm \mathrm{SD} \mathrm{mm} \mathrm{Hg}$ & $84 \pm 26$ & $74 \pm 32$ & $<.001$ \\
\hline $\mathrm{pH}$, mean $\pm \mathrm{SD}$ & $7.38 \pm 0.06$ & $7.27 \pm 0.17$ & $<.001$ \\
\hline CysC, mean $\pm \mathrm{SD} \mathrm{mg} / \mathrm{L}$ & $1.39 \pm 0.54$ & $2.21 \pm 1.05$ & $<.001$ \\
\hline Creatinine, mean $\pm \mathrm{SD} \mu \mathrm{mol} / \mathrm{L}$ & $93.8 \pm 51.5$ & $123.8 \pm 83.3$ & $<.001$ \\
\hline $\mathrm{BUN}$, mean $\pm \mathrm{SD} \mathrm{mmol} / \mathrm{L}$ & $7 \pm 8$ & $11 \pm 8$ & .00 \\
\hline Diabetes (no/yes), $n$ & $353 / 65$ & $53 / 6$ & .33 \\
\hline $\begin{array}{l}\mathrm{CHF}=\text { congestive heart failure } \\
\mathrm{RD}=\text { renal dysfunction } \\
\mathrm{CysC}=\text { cystatin } \mathrm{C} \\
\mathrm{BUN}=\text { blood urea nitrogen }\end{array}$ & & & \\
\hline
\end{tabular}

levels were significantly lower in non-survivors $(\mathrm{pH}$ $7.27 \pm 0.17, \mathrm{P}_{\mathrm{aO}_{2}}=74 \pm 32 \mathrm{~mm} \mathrm{Hg}$ ) compared with survivors ( $\mathrm{pH} 7.38 \pm 0.06, \mathrm{P}_{\mathrm{aO}_{2}}=84 \pm 26$ ). The plasma concentrations of CysC, creatinine, and blood urea nitrogen were higher in non-survivors $(\mathrm{CysC}=$ $2.21 \pm 1.05 \mathrm{mg} / \mathrm{L}$, creatinine $=123.8 \pm 83.3 \mu \mathrm{mol} / \mathrm{L}$, and blood urea nitrogen $=11 \pm 8 \mathrm{mmol} / \mathrm{L}$ ) than in survivors $(\mathrm{CysC}=1.39 \pm 0.54$, creatinine $=93.8 \pm 51.5 \mu \mathrm{mol} / \mathrm{L}$, and blood urea nitrogen $=7 \pm 8 \mathrm{mmol} / \mathrm{L}$ ).

Receiver operating characteristic curves were used to determine the cut-off values for the biochemical parameters. The optimal values of $\mathrm{Cys} C$ for predicting death were defined as the concentrations with the largest sensitivity plus specificity for the curves. The receiver operating characteristic curve analysis (Fig. 1) identified CysC levels of $\geq 1.59 \mathrm{mg} / \mathrm{L}$ as the optimal level that discriminated the survivors from the non-survivors (area under the receiver operating characteristic curve $=0.77,95 \% \mathrm{CI}=0.70-0.84$, $P<.001$ ). The entire cohort was then divided into 2 groups according to the serum CysC levels. There were 148 subjects with CysC levels of $\geq 1.59 \mathrm{mg} / \mathrm{L}$ and 329 with CysC levels of $<1.59 \mathrm{mg} / \mathrm{L}$. Table 2 shows non-statistically significant associations of CysC levels with sex and $\mathrm{P}_{\mathrm{aO}_{2}}(P=.14$ and $P=.37$, respectively) and statistically significant associations with age, $\mathrm{pH}, \mathrm{P}_{\mathrm{aCO}}$, and the concentration of creatinine and blood urea nitrogen $(P<.001)$.

In univariate analyses, the survival of subjects with $\mathrm{Cys} C$ levels $<1.59 \mathrm{mg} / \mathrm{L}$ and those with CysC levels $\geq 1.59 \mathrm{mg} / \mathrm{L}$ differed significantly. The probability of in-hospital death of subjects with CysC levels $\geq 1.59 \mathrm{mg} / \mathrm{L}$ was $28.4 \%$, whereas the corresponding probability of death in subjects 


\section{CysC Predicts Mortality in COPD Exacerbation}

with CysC levels $<1.59 \mathrm{mg} / \mathrm{L}$ was $5.2 \%(\mathrm{RR}=5.49$, $95 \% \mathrm{CI}=3.24-9.32)$. At the same time, $\mathrm{pH}, \mathrm{P}_{\mathrm{aCO}_{2}}, \mathrm{P}_{\mathrm{aO}_{2}}$, renal dysfunction, and congestive heart failure also predicted in-hospital mortality, whereas sex, age, and history of smoking did not (see Table 3).

The logistic regression revealed that the factors associated with in-hospital mortality were a $\mathrm{pH}$ of $<7.20$ (odds ratio 4.33, 95\% CI 2.27-8.24), $\mathrm{P}_{\mathrm{aO}_{2}}<60 \mathrm{~mm} \mathrm{Hg}$ (odds ratio 3.41, 95\% CI 1.61-7.22), and a CysC level of $\geq 1.59 \mathrm{mg} / \mathrm{L}$ (odds ratio $6.20,95 \%$ CI $2.61-14.75$ ) (Table 4).

Table 5 and Figures 2 and 3 show the results of the subgroup analyses stratified by the comorbidities of con-

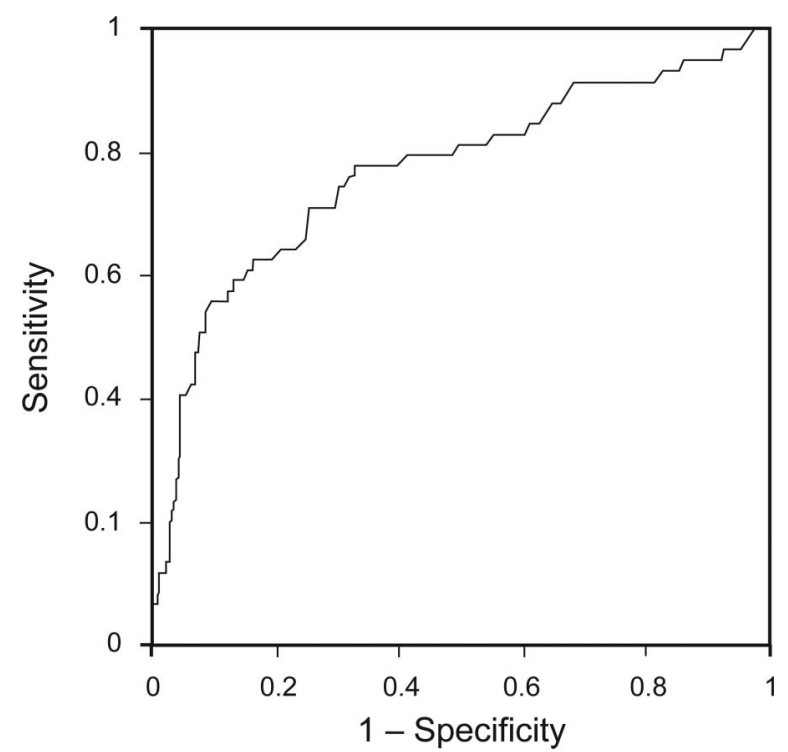

Fig. 1. A receiver operator characteristic curve for plasma cystatin $\mathrm{C}$ as an overall predictor of death in subjects with COPD exacerbation. Area under the receiver operator characteristic curve $=$ 0.77 (95\% Cl 0.70-0.84). gestive heart failure, renal dysfunction, and the levels of $\mathrm{pH}, \mathrm{P}_{\mathrm{aCO}}$, and $\mathrm{P}_{\mathrm{aO}_{2}}$. Our analysis showed that $\mathrm{CysC}$ was a mortality risk factor for subjects with COPD exacerbation with and without renal dysfunction or congestive heart failure. Our results also showed that $\mathrm{CysC}$ was a mortality risk factor for subjects with COPD exacerbation with various levels of $\mathrm{pH}, \mathrm{P}_{\mathrm{aCO}}$, and $\mathrm{P}_{\mathrm{aO}_{2}}$.

\section{Discussion}

This study is the most comprehensive prospective study to report associations between the $\mathrm{CysC}$ status determined during hospitalization for COPD exacerbation and shortterm prognosis. The main finding of the current study was that elevated $\mathrm{Cys} C$ is a strong independent prognostic factor for in-hospital mortality ( $\mathrm{RR}=5.49,95 \%$ CI 3.24 9.32). Even after adjusting for multiple, well-accepted predictors of mortality, a CysC level $\geq 1.59$ remained a strong predictor of in-hospital mortality (odds ratio $=6.20,95 \% \mathrm{CI}$ (2.61-14.75). To the best of our knowledge, this association between CysC elevation and mortality due to COPD exacerbation is a novel finding. Moreover, it may be important for risk stratification and the treatment of patients hospitalized with COPD exacerbation. Many studies have reported the predictive value of $\mathrm{CysC}$, and serum $\mathrm{CysC}$ has been reported not only as a marker of glomerular filtration rate but also as an independent risk factor for all-cause and cardiovascular mortality among elderly persons with chronic kidney disease with or without renal impairment. ${ }^{18}$ One study reported that higher CysC levels independently predicted $5 \mathrm{y}$ all-cause and cardiovascular death in subjects with peripheral arterial disease. ${ }^{19}$ A positive correlation between CysC and inflammatory parameters, including interleukin-6, resistin, tumor necrosis factor, and C-reactive protein, has been reported. ${ }^{20}$

Table 2. Baseline Characteristics Stratified by the Cystatin C Concentration

\begin{tabular}{|c|c|c|c|}
\hline Subject Characteristics & CysC $\geq 1.59 \mathrm{mg} / \mathrm{L}(n=148)$ & CysC $<1.59 \mathrm{mg} / \mathrm{L}(n=329)$ & $P$ \\
\hline Age, mean \pm SD y & $81.5 \pm 7.9$ & $75.4 \pm 9.4$ & $<.001$ \\
\hline Male/female sex, $n$ & $116 / 32$ & $241 / 88$ & .14 \\
\hline CHF (yes/no), $n$ & $49 / 99$ & $51 / 278$ & $<.001$ \\
\hline $\mathrm{RD}$ (yes/no), $n$ & $79 / 69$ & $14 / 315$ & $<.001$ \\
\hline $\mathrm{P}_{\mathrm{aCO}_{2}}$, mean $\pm \mathrm{SD} \mathrm{mm} \mathrm{Hg}$ & $56 \pm 28$ & $49 \pm 16$ & $<.001$ \\
\hline $\mathrm{P}_{\mathrm{aO}_{2}}$, mean $\pm \mathrm{SD} \mathrm{mm} \mathrm{Hg}$ & $81 \pm 29$ & $84 \pm 27$ & .37 \\
\hline $\mathrm{pH}^{2}$ & $7.33 \pm 0.12$ & $7.38 \pm 0.06$ & $<.001$ \\
\hline CysC, mean $\pm \mathrm{SD}$ mg/L & $2.25 \pm 0.74$ & $1.15 \pm 0.23$ & $<.001$ \\
\hline Creatinine, mean $\pm \mathrm{SD} \mu \mathrm{mol} / \mathrm{L}$ & $146.0 \pm 76.4$ & $76.1 \pm 24.6$ & $<.001$ \\
\hline $\mathrm{BUN}$, mean $\pm \mathrm{SD} \mathrm{mmol} / \mathrm{L}$ & $11 \pm 7$ & $6 \pm 8$ & $<.001$ \\
\hline $\begin{array}{l}\mathrm{CHF}=\text { congestive heart failure } \\
\mathrm{RD}=\text { renal dysfunction } \\
\mathrm{CysC}=\text { cystatin } \mathrm{C} \\
\mathrm{BUN}=\text { blood urea nitrogen }\end{array}$ & & & \\
\hline
\end{tabular}




\section{CysC Predicts Mortality in COPD Exacerbation}

Table 3. Mortality Risk in Subjects With COPD Exacerbation

\begin{tabular}{|c|c|c|c|c|c|}
\hline Characteristics & Total, $n$ & Survivors, $n(\%)$ & Non-survivors, $n(\%)$ & RR $(95 \%$ CI $)$ & $P$ \\
\hline Age & & & & & .39 \\
\hline$\leq 59 \mathrm{y}$ & 23 & $21(91.3)$ & $2(8.7)$ & 1 & \\
\hline $60-69$ y & 70 & 65 (92.9) & $5(7.1)$ & $0.82(0.17-3.95)$ & \\
\hline $70-79 y$ & 144 & $128(88.9)$ & $16(11.1)$ & $1.28(0.31-5.19)$ & \\
\hline $80-89$ y & 207 & $177(85.5)$ & $30(14.5)$ & $1.67(0.43-6.53)$ & \\
\hline$\geq 90 \mathrm{y}$ & 33 & $27(81.8)$ & $6(18.2)$ & $2.09(0.46-9.46)$ & \\
\hline Smoking & & & & & .30 \\
\hline No & 88 & $80(41.4)$ & $8(58.6)$ & 1 & \\
\hline Yes & 389 & $338(47.5)$ & $51(52.5)$ & $1.44(0.71-2.93)$ & \\
\hline Sex & & & & & .87 \\
\hline Male & 357 & $312(87.4)$ & 45 (12.6) & 1 & \\
\hline Female & 120 & $106(88.3)$ & $14(11.7)$ & $0.94(0.58-1.52)$ & \\
\hline $\mathrm{pH}$ & & & & & $<.001$ \\
\hline$>7.35$ & 358 & 335 (93.6) & $23(6.4)$ & 1 & \\
\hline $7.20-7.35$ & 96 & $80(83.3)$ & $16(16.7)$ & $2.13(1.39-3.25)$ & \\
\hline$<7.20$ & 23 & $3(13)$ & $20(87)$ & $52.40(16.24-169.0)$ & \\
\hline $\mathrm{P}_{\mathrm{aCO}_{2}}$ & & & & & $<.001$ \\
\hline$<50 \mathrm{~mm} \mathrm{Hg}$ & 312 & $296(94.9)$ & $16(5.1)$ & 1 & \\
\hline$>50 \mathrm{~mm} \mathrm{Hg}$ & 165 & $122(73.9)$ & $43(26.1)$ & $5.08(2.96-8.74)$ & \\
\hline $\mathrm{P}_{\mathrm{aO}_{2}}$ & & & & & $<.001$ \\
\hline$\geq 60 \mathrm{~mm} \mathrm{Hg}$ & 390 & $358(91.8)$ & $32(8.2)$ & 1 & \\
\hline$<60 \mathrm{~mm} \mathrm{Hg}$ & 87 & $60(69)$ & $27(31)$ & $3.78(2.40-5.97)$ & \\
\hline $\mathrm{CHF}$ & & & & & $<.001$ \\
\hline No & 377 & $348(92.3)$ & $29(7.7)$ & 1 & \\
\hline Yes & 100 & $70(70)$ & $30(30)$ & $3.90(2.46-6.18)$ & \\
\hline $\mathrm{RD}$ & & & & & $<.001$ \\
\hline No & 384 & 353 (91.9) & $31(8.1)$ & 1 & \\
\hline Yes & 93 & $65(69.9)$ & $28(30.1)$ & $3.73(2.36-5.90)$ & \\
\hline CysC & & & & & $<.001$ \\
\hline$<1.59 \mathrm{mg} / \mathrm{L}$ & 329 & $312(94.8)$ & $17(5.2)$ & 1 & \\
\hline$\geq 1.59 \mathrm{mg} / \mathrm{L}$ & 148 & $106(71.6)$ & $42(28.4)$ & $5.49(3.24-9.32)$ & \\
\hline $\mathrm{FEV}_{1}$ predicted & & & & & .01 \\
\hline$>80$ & 78 & $72(92.3)$ & $6(7.7)$ & 1 & \\
\hline $50-80$ & 281 & $250(89)$ & $31(11)$ & $1.43(0.62-3.31)$ & .39 \\
\hline $30-50$ & 82 & $63(76.8)$ & $19(23.2)$ & $3.01(1.27-7.15)$ & $<.01$ \\
\hline$<30$ & 36 & 33 (91.7) & $3(8.3)$ & $1.08(0.29-4.09)$ & .91 \\
\hline $\begin{array}{l}\mathrm{CHF}=\text { congestive he } \\
\mathrm{RD}=\text { renal dysfuncti } \\
\mathrm{CysC}=\text { cystatin } \mathrm{C} \\
\mathrm{BUN}=\text { blood urea ni }\end{array}$ & & & & & \\
\hline
\end{tabular}

Carrasco-Sánchez et $\mathrm{al}^{21}$ reported that the serum CysC level at the time of admission in subjects with heart failure with preserved ejection fraction is a strong and independent predictor of an unfavorable outcome. This relationship is also present in patients without advanced renal dysfunction. $^{21}$ Akgul et $\mathrm{al}^{22}$ reported that the presence of high CysC levels at the time of admission was associated with increased in-hospital and 1-month cardiovascular mortality in subjects with ST-elevation myocardial infarctions undergoing primary percutaneous coronary intervention. Increased levels of $\mathrm{Cys} C$ were an independent predictor of cardiac events within a $1-y$ follow-up in this contemporary series of Mediterranean subjects with non-ST-elevation acute coronary syndrome. ${ }^{11}$ The concentration of $\mathrm{CysC}$ was strongly associated with long-term all-cause and cardiovascular mortality in subjects referred for coronary angiography, irrespective of the renal function status based on creatinine measurements. ${ }^{23}$ However, the literature describing the role of CysC in COPD is sparse, and few studies have addressed this issue to date. In China, Zhang et al $^{14}$ reported that high $\mathrm{CysC}$ levels were directly associated with decreased lung function in elderly Chinese men with COPD. In a large representative non-institutionalized United States population, Rokadia and Agarwal ${ }^{24}$ 


\section{CysC Predicts Mortality in COPD Exacerbation}

demonstrated an association between emphysema and serum CysC. Active smokers with emphysema had significantly higher CysC levels. Takeyabu et $\mathrm{al}^{25}$ reported that increased levels of $\mathrm{CysC}$ were present in the bronchoalveolar lavage fluid from subjects with subclinical emphysema. Pérez-Calvo et al ${ }^{15}$ analyzed CysC levels at the time of admission in 107 subjects with exacerbation of chronic lung disease. During a 12-month follow-up, the mortality, new hospital admissions, and prescriptions of diuretics were recorded. The results showed that $\mathrm{Cys} C$ had no predictive value in terms of mortality for subjects with chronic respiratory disease.

Table 4. Logistic Regression Analyses of the Risk Factors Associated With Mortality in Subjects With COPD Exacerbation

\begin{tabular}{lccrccc}
\hline \hline Factors & \multicolumn{1}{c}{$\mathrm{B}$} & $\mathrm{SE}$ & Wald & $P$ & $\operatorname{Exp}(\mathrm{B})$ & $\begin{array}{c}95 \% \mathrm{CI} \\
\text { for } \operatorname{Exp}(\mathrm{B})\end{array}$ \\
\hline $\mathrm{CysC}$ & 1.82 & 0.44 & 17.02 & $<.001$ & 6.20 & $2.61-14.75$ \\
$\mathrm{P}_{\mathrm{aCO}_{2}}$ & 0.54 & 0.44 & 1.53 & .22 & 1.72 & $0.73-4.79$ \\
$\mathrm{Age}$ & 0.12 & 0.20 & 0.35 & .56 & 1.13 & $0.76-1.67$ \\
$\mathrm{P}_{\mathrm{aO}}$ & 1.23 & 0.38 & 10.25 & .001 & 3.41 & $1.61-7.22$ \\
$\mathrm{pH}$ & 1.47 & 0.33 & 19.84 & $<.001$ & 4.33 & $2.27-8.64$ \\
$\mathrm{RD}$ & -0.72 & 0.47 & 2.41 & .12 & 0.49 & $0.19-1.21$ \\
$\mathrm{Sex}$ & 0.39 & 0.42 & 0.88 & .35 & 1.48 & $0.65-3.34$ \\
$\mathrm{CHF}$ & 1.27 & 0.37 & 11.90 & .001 & 3.55 & $1.73-7.29$ \\
Constant & -4.98 & 0.71 & 48.57 & $<.001$ & 0.007 &
\end{tabular}

$\mathrm{RD}=$ renal dysfunction

$\mathrm{CHF}=$ congestive heart failure
In the present study, our results showed that the levels of $\mathrm{CysC}$ were associated with the comorbidities of renal dysfunction, congestive heart failure, old age, lower $\mathrm{pH}$, and higher $\mathrm{P}_{\mathrm{aCO}_{2}}$ (Table 2). We also found that age, heart failure, hypercapnia, hypoxemia, and $\mathrm{pH}<7.20$ were also risk factors for the death of subjects with COPD exacerbation: These factors may be involved in the mechanism for the CysC elevation in non-survivors versus survivors. Our results were consistent with the previous studies. ${ }^{26,27}$ Li et $\mathrm{al}^{26}$ reported that hypercapnia and chronic pulmonary heart disease were independent risk factors for mortality in hospitalized subjects with COPD exacerbation. Fruchter and Yigla $^{27}$ also found that the presence of ischemic heart disease and $\mathrm{P}_{\mathrm{aO}_{2}}$ levels upon admission were independent predictors of mortality for subjects with COPD exacerbation. In our study, elevated CysC levels were most often detected in older subjects and in subjects who were more hypoxemic, hypercapnic, and acidotic and had high levels of blood urea nitrogen and creatinine; however, there were no significant correlations with $\mathrm{P}_{\mathrm{aO}_{2}}$ or sex (Table 2). To our knowledge, no studies of the relationship between CysC and the results of a blood gas analysis have been published. Akgul et al22 reported that subjects in the high $\mathrm{CysC}$ group were older. Sarnak et al ${ }^{28}$ determined that elevated $\mathrm{CysC}$ was an independent predictor of heart failure after adjusting for traditional and nontraditional risk factors for heart failure. Ix et $\mathrm{a}^{29}$ found that higher CysC had a stronger association with diastolic compared with systolic dysfunction in the Heart and Soul Study.

To reduce the influence of confounding factors, we performed the subgroup analysis stratified by the comorbidi-

Table 5. Subgroup Analysis of the Mortality Risk in Subjects With COPD Exacerbation

\begin{tabular}{|c|c|c|c|c|c|}
\hline \multirow{2}{*}{ Characteristics } & \multicolumn{2}{|c|}{ Cystatin $\mathrm{C}<1.59 \mathrm{mg} / \mathrm{L}$} & \multicolumn{2}{|c|}{ Cystatin $\mathrm{C} \geq 1.59 \mathrm{mg} / \mathrm{L}$} & \multirow{2}{*}{$P$} \\
\hline & Survivors, $n(\%)$ & Non-survivors, $n(\%)$ & Survivors, $n(\%)$ & Non-survivors, $n(\%)$ & \\
\hline \multicolumn{6}{|l|}{$\mathrm{pH}$} \\
\hline$\geq 7.35$ & 253 (96.9) & $8(3.1)$ & $82(84.5)$ & $15(15.5)$ & $<.001$ \\
\hline$<7.35$ & $59(86.8)$ & $9(13.2)$ & $24(47.1)$ & $27(52.9)$ & $<.001$ \\
\hline \multicolumn{6}{|l|}{$\mathrm{P}_{\mathrm{aCO}_{2}}$} \\
\hline$<50 \mathrm{~mm} \mathrm{Hg}$ & $214(96.8)$ & $7(3.2)$ & $82(90.1)$ & $9(9.9)$ & .014 \\
\hline$\geq 50 \mathrm{~mm} \mathrm{Hg}$ & $98(90.7)$ & $10(9.3)$ & $24(42.1)$ & $33(57.9)$ & $<.001$ \\
\hline \multicolumn{6}{|l|}{$\mathrm{P}_{\mathrm{aO}_{2}}$} \\
\hline$\geq 60 \mathrm{~mm} \mathrm{Hg}$ & 269 & $8(2.9)$ & $89(79.8)$ & $24(21.2)$ & $<.001$ \\
\hline$<60 \mathrm{~mm} \mathrm{Hg}$ & 43 & $9(17.3)$ & 17 (48.6) & $18(51.4)$ & $<.001$ \\
\hline \multicolumn{6}{|l|}{ CHF } \\
\hline No & $268(96.4)$ & $10(3.6)$ & $80(80.8)$ & $19(19.2)$ & $<.001$ \\
\hline Yes & $44(86.3)$ & $7(13.7)$ & $26(53.1)$ & $23(46.9)$ & $<.001$ \\
\hline \multicolumn{6}{|l|}{$\mathrm{RD}$} \\
\hline No & 299 (94.9) & $16(5.1)$ & $54(78.3)$ & $15(21.7)$ & $<.001$ \\
\hline Yes & $13(92.9)$ & $1(7.1)$ & $52(65.8)$ & $27(34.2)$ & .042 \\
\hline
\end{tabular}




\section{CysC Predicts Mortality in COPD Exacerbation}

ties of congestive heart failure, renal dysfunction, and levels of $\mathrm{pH}, \mathrm{P}_{\mathrm{aO}_{2}}$, and $\mathrm{P}_{\mathrm{aCO}_{2}}$. We found that the comorbidities of renal dysfunction, congestive heart failure, and levels of $\mathrm{pH}, \mathrm{P}_{\mathrm{aCO}}$, and $\mathrm{P}_{\mathrm{aO}_{2}}$ did not alter the conclusion that CysC was a mortality risk factor for subjects with COPD exacerbation. In general, patients with COPD exacerbation may suffer several types of comorbidities, including congestive heart failure and renal dysfunction, and may have a high $\mathrm{P}_{\mathrm{aCO}_{2}}$ and a low $\mathrm{pH}$. At the same time, the comorbidities of congestive heart failure, renal dysfunction, high $\mathrm{P}_{\mathrm{aCO}}$, and low $\mathrm{pH}$ also could affect the level of $\mathrm{CysC}$, which may be related to the source of elevated CysC.

In our study, the levels of $\mathrm{CysC}$, which is a form of cysteine protease inhibitor, were higher in the non-survi-
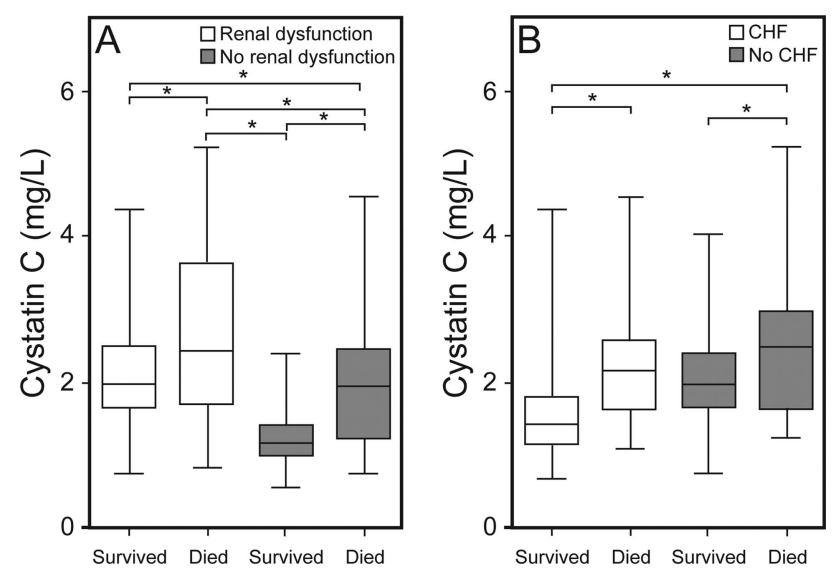

Fig. 2. Cystatin $C$ levels (mg/L) in survivor and non-survivor subjects with COPD exacerbation stratified by the comorbid presence of renal dysfunction $(A)$ and congestive heart failure $(B)$ at the time of admission. Boxes show first and third quartiles, center lines denote the median, and whiskers show the minimum and maximum. ${ }^{*} P<.05$. vor group than in the survivors. Cysteine proteases (cathepsins) have a role in the pathogenesis of COPD. ${ }^{30}$ Cathepsin- $\mathrm{L}$ has been detected in bronchoalveolar lavage fluid from patients with emphysema, ${ }^{31}$ and alveolar macrophages in patients with COPD secrete more cysteine proteases than macrophages from normal smokers or nonsmokers. ${ }^{31}$ Furthermore, some authors have suggested that an increased concentration of $\mathrm{CysC}$ may reflect an attempt to counterbalance a potentially damaging level of increased elastolytic activity. ${ }^{32}$ However, we did not determine the levels of cysteine protease inhibitor activity. We therefore cannot conclude that there was a relationship between the inhibitor activity and poor prognosis.

Our study had several limitations. First, the diagnosis of COPD was established according to historical spirometry results. We were unable to recruit patients with stable COPD before hospitalization for COPD exacerbation for the purpose of this study. Second, we only recorded the mortality of hospitalized subjects with COPD exacerbation. The follow-up time was relatively short, and the study was mostly cross-sectional. Third, the intervention for COPD exacerbation was not identical for all subjects, which is another confounder. Fourth, we did not collect information regarding the subjects' use of glucocorticoids before COPD exacerbation, and the use of glucocorticoids may affect the level of CysC. Finally, the relatively small number of subjects included in each group also made it difficult to draw firm conclusions from the data.

\section{Conclusions}

An elevated CysC level present during COPD exacerbation is an important and independent determinant of subsequent mortality in a hospital setting.
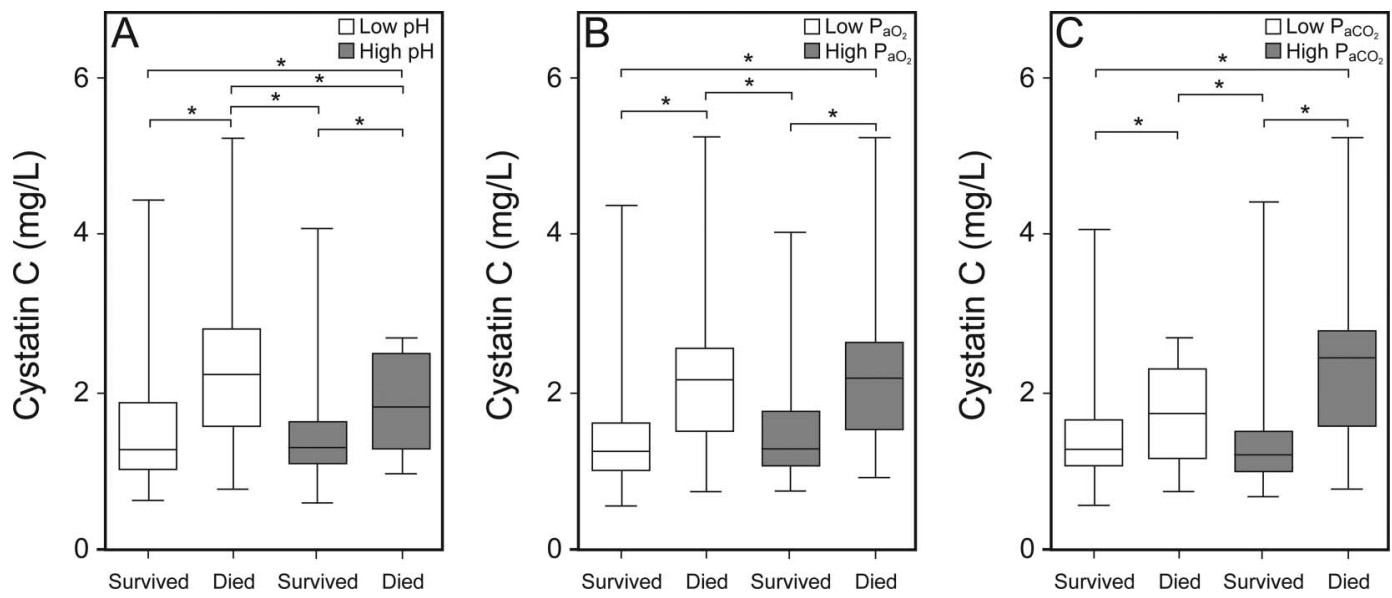

Fig. 3. Cystatin $\mathrm{C}$ levels $(\mathrm{mg} / \mathrm{L})$ in the survivor and non-survivor subjects with COPD exacerbation stratified by the levels of $\mathrm{pH}(\mathrm{A}), \mathrm{P}_{\mathrm{aO}}(\mathrm{B})$, and $\mathrm{P}_{\mathrm{aCO}_{2}}$ (C). Low $\mathrm{pH}$ is $<7.35$, and high $\mathrm{pH}$ is $>7.35$; low $\mathrm{P}_{\mathrm{aO}}$ is $<60 \mathrm{~mm} \mathrm{Hg}$, and high $\mathrm{P}_{\mathrm{aO}_{2}}$ is $\geq 60 \mathrm{~mm} \mathrm{Hg}$; low $\mathrm{P}_{\mathrm{acO}}$ is $<50 \mathrm{~mm} \mathrm{Hg}$, and high $\mathrm{P}_{\mathrm{acO}_{2}}$ is $\geq 50 \mathrm{~mm} \mathrm{Hg}$. Boxes show first and third quartiles, center lines denote the median, and whiskers show the minimum and maximum. ${ }^{*} P<.05$. 


\section{CysC Predicts Mortality in COPD Exacerbation}

\section{REFERENCES}

1. Murray CJ, Lopez AD. Alternative projections of mortality and disability by cause 1990-2020: global burden of disease study. Lancet 1997;349(9064):1498-1504.

2. Sin DD, Anthonisen NR, Soriano JB, Agusti AG. Mortality in COPD: role of comorbidities. Eur Respir J 2006;28(6):1245-1257.

3. Holguin F, Folch E, Redd SC, Mannino DM. Comorbidity and mortality in COPD-related hospitalizations in the United States, 1979 to 2001. Chest 2005;128(4):2005-2011.

4. Connors AF Jr., Dawson NV, Thomas C, Harrell FE Jr., Desbiens N, Fulkerson WJ, et al. Outcomes following acute exacerbation of severe chronic obstructive lung disease: the SUPPORT investigators (Study to Understand Prognoses and Preferences for Outcomes and Risks of Treatments). Am J Respir Crit Care Med 1996;154(4 Pt 1): 959-967.

5. Pingleton SK. Complications of acute respiratory failure. Am Rev Respir Dis 1988;137(6):1463-1493.

6. Gjerde B, Bakke PS, Ueland T, Hardie JA, Eagan TM. The prevalence of undiagnosed renal failure in a cohort of COPD patients in western Norway. Respir Med 2012;106(3):361-366.

7. Kiyosue A, Hirata Y, Ando J, Fujita H, Morita T, Takahashi M, et al. Plasma cystatin $\mathrm{C}$ concentration reflects the severity of coronary artery disease in patients without chronic kidney disease. Circ J 2010;74(11):2441-2447.

8. Hojs R, Bevc S, Ekart R, Gorenjak M, Puklavec L. Serum cystatin C-based equation compared to serum creatinine-based equations for estimation of glomerular filtration rate in patients with chronic kidney disease. Clin Nephrol 2008;70(1):10-17.

9. Keller T, Messow CM, Lubos E, Nicaud V, Wild PS, Rupprecht HJ, et al. Cystatin $\mathrm{C}$ and cardiovascular mortality in patients with coronary artery disease and normal or mildly reduced kidney function: results from the AtheroGene study. Eur Heart J 2009;30(3):314-320.

10. Ichimoto E, Jo K, Kobayashi Y, Inoue T, Nakamura Y, Kuroda N, et al. Prognostic significance of cystatin $\mathrm{C}$ in patients with ST-elevation myocardial infarction. Circ J 2009;73(9):1669-1673.

11. Taglieri N, Fernandez-Berges DJ, Koenig W, Consuegra-Sanchez L, Fernandez JM, Robles NR, et al. Plasma cystatin C for prediction of 1-year cardiac events in Mediterranean patients with non-ST elevation acute coronary syndrome. Atherosclerosis 2010;209(1):300-305.

12. Shlipak MG, Katz R, Fried LF, Jenny NS, Stehman-Breen C, Newman $\mathrm{AB}$, et al. Cystatin-C and mortality in elderly persons with heart failure. J Am Coll Cardiol 2005;45(2):268-271.

13. Lassus J, Harjola VP, Sund R, Siirilä-Waris K, Melin J, Peuhkurinen $\mathrm{K}$, et al. Prognostic value of cystatin $\mathrm{C}$ in acute heart failure in relation to other markers of renal function and NT-proBNP. Eur Heart J 2007;28(15):1841-1847.

14. Zhang M, Fu SH, Cui H, Zhu BP, Liu L, Wang DL. Serum cystatin $\mathrm{C}$ and indices of lung function in elderly Chinese men with chronic obstructive pulmonary disease. Aging Clin Exp Res 2014;26(2):193199.

15. Pérez-Calvo JI, Sánchez-Marteles M, Ruiz-Ruiz FJ, Morales-Rull JL, Nieto-Rodríguez JA. Differential prognostic utility of NTproBNP and Cystatin $\mathrm{C}$ in patients with acute exacerbation of chronic pulmonary disease. JRSM Short Rep 2010;1(5):44.

16. Levey AS, Bosch JP, Lewis JB, Greene T, Rogers N, Roth D. A more accurate method to estimate glomerular filtration rate from serum creatinine: a new prediction equation: Modification of Diet in Renal Disease Study Group. Ann Intern Med 1999;130(6):461-470.
17. Chinese Society of Cardiology of Chinese Medical Association, Editorial Board of Chinese Journal of Cardiology. [Guidelines for the diagnosis and management of chronic heart failure]. Zhonghua Xin Xue Guan Bing Za Zhi 2007;35(12):1076-1095.

18. Lassus J, Harjola VP. Cystatin C: a step forward in assessing kidney function and cardiovascular risk. Heart Fail Rev 2012;17(2):251261.

19. Urbonaviciene G, Shi GP, Urbonavicius S, Henneberg EW, Lindholt JS. Higher cystatin C level predicts long-term mortality in patients with peripheral arterial disease. Atherosclerosis 2011;216(2):440445 .

20. Balta S, Demirkol S, Ay SA, Cakar M, Sarlak H, Celik T. Serum cystatin-C levels correlate with endothelial dysfunction in patients with the metabolic syndrome. J Intern Med 2013;274(2):200-201.

21. Carrasco-Sánchez FJ, Galisteo-Almeda L, Páez-Rubio I, MartínezMarcos FJ, Camacho-Vázquez C, Ruiz-Frutos C, Pujol-Da La Llave E. Prognostic value of cystatin $\mathrm{C}$ on admission in heart failure with preserved ejection fraction. J Card Fail 2011;17(1):31-38.

22. Akgul O, Uyarel H, Ergelen M, Pusuroglu H, Gul M, Turen S, et al. Predictive value of elevated cystatin $\mathrm{C}$ in patients undergoing primary angioplasty for ST-elevation myocardial infarction. J Crit Care 2013;28(5):882.e13-882.e20

23. Woitas RP, Kleber ME, Meinitzer A, Grammer TB, Silbernagel G, Pilz S, et al. Cystatin $\mathrm{C}$ is independently associated with total and cardiovascular mortality in individuals undergoing coronary angiography: the Ludwigshafen risk and cardiovascular health (LURIC) study. Atherosclerosis 2013;229(2):541-548.

24. Rokadia HK, Agarwal S. Serum cystatin C and emphysema: results from the National Health and Nutrition Examination Survey (NHANES). Lung 2012;190(3):283-290.

25. Takeyabu K, Betsuyaku T, Nishimura M, Yoshioka A, Tanino M, Miyamoto K, Kawakami Y. Cysteine proteinases and cystatin C in bronchoalveolar lavage fluid from subjects with subclinical emphysema. Eur Respir J 1998;12(5):1033-1039.

26. Li J, Zhao HJ, Wang FY, Dong HM, Cai SX. [Risk factors for in-hospital mortality in patients with acute exacerbation of chronic obstructive pulmonary disease]. Zhonghua Yi Xue Za Zhi 2013; 93(18):1374-1377.

27. Fruchter O, Yigla M. Predictors of long-term survival in elderly patients hospitalized for acute exacerbations of chronic obstructive pulmonary disease. Respirology 2008;13(6):851-855.

28. Sarnak MJ, Katz R, Stehman-Breen CO, Fried LF, Jenny NS, Psaty $\mathrm{BM}$, et al. Cystatin $\mathrm{C}$ concentration as a risk factor for heart failure in older adults. Ann Intern Med 2005;142(7):497-505.

29. Ix JH, Shlipak MG, Chertow GM, Ali S, Schiller NB, Whooley MA. Cystatin C, left ventricular hypertrophy, and diastolic dysfunction: data from the Heart and Soul Study. J Card Fail 2006;12(8):601-607.

30. William Macnee, Jørgen Vestbo, Alvar Agusti. 43 - COPD: Pathogenesis and Natural History. Murray and Nadel's Textbook of Respiratory Medicine (Sixth Edition), Volume 1, 2016, Pages 751766.e7.

31. Finlay GA, O'Driscoll LR, Russell KJ, D’Arcy EM, Masterson JB, FitzGerald MX, O'Connor CM. Matrix metalloproteinase expression and production by alveolar macrophages in emphysema. Am J Respir Crit Care Med 1997;156(1):240-247.

32. Díez J. Altered degradation of extracellular matrix in myocardial remodelling: the growing role of cathepsins and cystatins. Cardiovasc Res 2010;87(4):591-592. 